\title{
MANIFESTAÇÕES PATOLÓGICAS NO SISTEMA CONSTRUTIVO CASA EXPRESS - ESTUDO DE CASO EM EMPREENDIMENTOS LOCALIZADOS EM TERESINA-PI
}

\author{
VELOSO, THAIS SILVA \\ Engenheira Civil \\ Unyleya \\ Piauí; Brasil. \\ e-mail: thaisveloso.eng@ gmail.com
}

\author{
FERREIRA, CAROL CHAVES MESQUITA E \\ Engenheira Civil/Arquiteta \\ Centro Universitário Uninovafapi \\ Piauí; Brasil. \\ e-mail: carol_arqeng@yahoo.com.br
}

\author{
BITENCOURTE, FRANCISCO CARLOS LOPES \\ Engenheiro Civil \\ Centro Universitário Uninovafapi \\ Piauí; Brasil. \\ e-mail: carlosbitencourte@gmail.com
}

\section{RESUMO}

Este trabalho apresenta um estudo feito em três empreendimentos construídos com um sistema inovador de painéis pré- moldados denominado Casa Express, na cidade de Teresina, onde foram mapeadas e estudadas as manifestações patológicas presentes nestas obras, descritas suas prováveis origens, bem como foram apontadas as soluções mais apropriadas para cada uma delas. Para a coleta de dados foram feitas vistorias in loco em um dos empreendimentos para o levantamento de manifestações patológicas, e os dados dos outros dois empreendimentos foram coletados junto ao setor de danos físicos da Caixa Econômica Federal (sede de Teresina), visto que as manifestações ocorridas já tinham passado por reparos. A análise dos dados coletados e o levantamento in loco feito através da ficha de identificação indicaram que o sistema tem funcionado efetivamente, apesar de não normatizado, e que as falhas encontradas estão relacionadas principalmente com execução. As manifestações patológicas mais presentes foram: fissuras, infiltrações, incompatibilidade de projetos e problemas relacionados a concretagem e montagem dos painéis.

Palavras-chaves: Sistema construtivo inovador. Painéis pré-moldados. Casa Express. Manifestações patológicas. Correções adequadas.

\begin{abstract}
This work presents a study carried out in three enterprises built with an innovative system panels named Casa Express, in the city of Teresina. There were mapped and studied the pathological manifestations present in these work environments, described their probable origins, as well as the most appropriate solutions for each of them. In order to gather data, in loco surveys were carried out in one of the enterprises to get information about the pathological manifestations, and data from the other two enterprises were collected from the Physical Damage sector of Caixa Econômica Federal (Teresina headquarters), since the manifestations had already been repaired. The analysis of the collected data and the in loco survey made through the identification form indicated that the system has worked effectively, although not standardized, and that the failures found are related mainly to execution. The most present pathological manifestations were: fissures, infiltrations, incompatibility of projects and problems related to concreting and the assembly of the panels.
\end{abstract}

Keywords: Innovative construction system. Precast panels. Casa Express. Pathological manifestations. Appropriate corrections. 


\section{INTRODUÇÃO}

Devido à grande demanda de unidades habitacionais a serem construídas e pressa para cumprimento dos prazos de entrega, buscou-se alternativas como substituir o sistema convencional por outros sistemas construtivos, como o de alvenaria estrutural, composto basicamente por blocos de concreto, argamassa ligante e sistema pré-moldado de concreto armado.

Segundo DATec (2016), esse sistema é composto por painéis estruturais pré-moldados, mistos de concreto armado e lajotas cerâmicas, e sua fabricação ocorre sobre uma pista de concreto, em uma fábrica fixa ou no canteiro de obras. As movimentações desses painéis são feitas através de caminhão guindaste ou guincho motorizado, e para sua montagem caminhão tipo munck.

Por não serem normatizados, passam por uma avaliação técnica regulamentada pela DATec $\mathrm{N}^{\circ}$ 23-A. Nela apresentamse as condições e limitações de uso do sistema. Esse sistema é utilizado para unidades familiares térreas, sobrados, casas isoladas ou germinadas, e edifícios multifamiliares de até dois pavimentos (térreo +1 pavimento).

O sistema possui algumas limitações técnicas, entre elas: o comprimento dos painéis não poderá ultrapassar $7000 \mathrm{~mm}$; não são permitidas modificações nas paredes como abertura de vãos e rasgos para instalações hidráulicas e elétricas; e os painéis não podem ser removidos por serem estruturais.

O sistema de painéis pré-moldados Casas Express é uma tecnologia construtiva relativamente nova, presente em um grande número de empreendimentos habitacionais populares no Piaú. Trata-se de um sistema inovador, visto que ainda não existe uma norma que regulamente e oriente a sua execução.

Por ser um sistema construtivo não convencional é de grande importância que se realizem estudos sobre as manifestações patológicas encontradas em painéis pré-moldados Casa Express, para que sejam definidas suas possíveis causas e adequadas soluções.

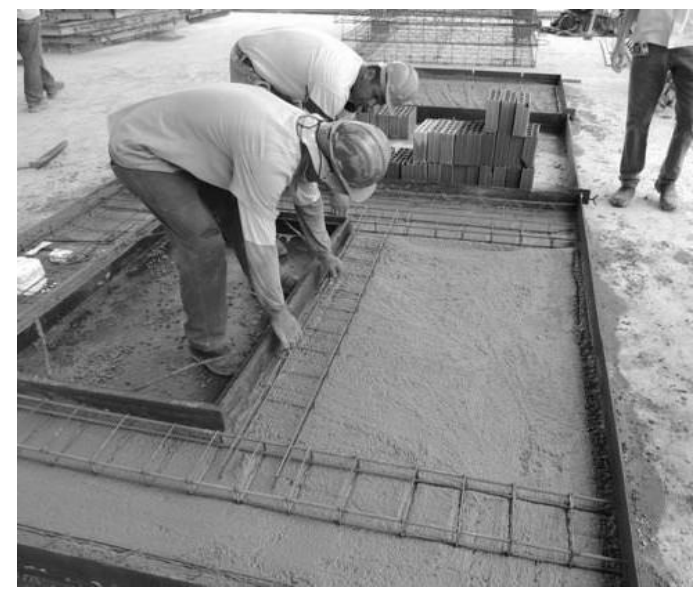

Figura 1: Posicionamento das armaduras da DATec 2016.

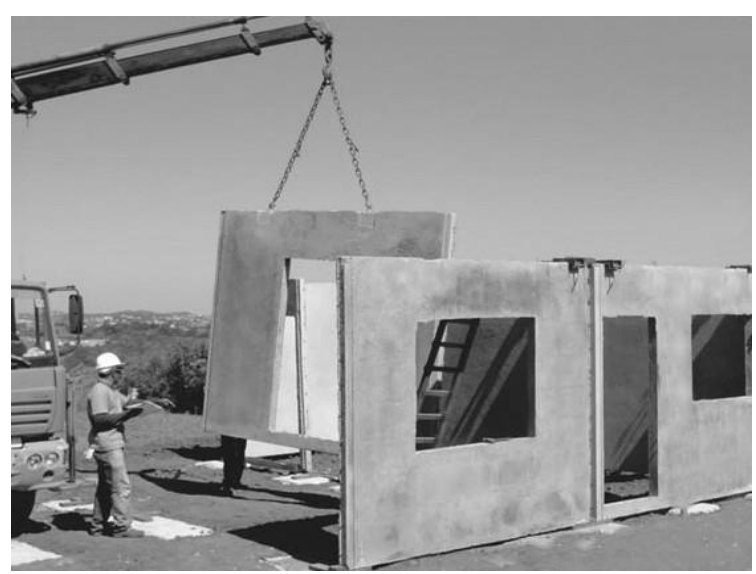

Figura 2: Içamento dos painéis da DATec 2016.

As patologias são o estudo das dos danos ocorridos em uma edificação. As causas de deterioração estrutural podem ocorrer de diversas maneiras, a partir do envelhecimento natural, acidentes, ou negligência dos profissionais responsáveis pela execução, que buscam economizar e acabam utilizando materiais com qualidade inferior e especificações desconhecidas.

Assim, é necessária análise das origens e das diversidades de manifestações patológicas de uma estrutura, a fim de conhecer as circunstâncias das falhas e a degradação das estruturas (SOUZA et al, 1998).

Este estudo em três empreendimentos foi realizado para analisar as manifestações patológicas encontradas em três empreendimentos localizados na cidade de Teresina-Piauí, que utilizaram o método construtivo painéis pré- moldados (Casa Express).

Para a coleta de dados foram feitas vistorias in loco em um empreendimento para o levantamento de manifestações patológicas, e os dados dos outros empreendimentos foram coletados junto à Caixa Econômica Federal (sede de Teresina), 
visto que as manifestações ocorridas já tinham passado por reparos.

Os instrumentos utilizados foram prancheta, câmera fotográfica, caneta, lapiseira e ficha de identificação para o levantamento de dados em campo.

$\mathrm{Na}$ análise das patologias encontradas foram utilizadas pesquisas bibliográficas, livros, revistas, artigos, dissertações e teses, estudos feitos por instituições, manuais técnicos e normas da ABNT que abrangesse o tema e o sistema construtivo em estudo.

\section{METODOLOGIA}

Este estudo em três empreendimentos foi realizado para analisar as manifestações patológicas encontradas em três empreendimentos localizados na cidade de Teresina-Piauí, que utilizaram o método construtivo painéis pré- moldados (Casa Express).

Para a coleta de dados foram feitas vistorias in loco em um empreendimento para o levantamento de manifestações patológicas, e os dados dos outros empreendimentos foram coletados junto à Caixa Econômica Federal (sede de Teresina), visto que as manifestações ocorridas já tinham passado por reparos.

Os instrumentos utilizados foram prancheta, câmera fotográfica, caneta, lapiseira e ficha de identificação para o levantamento de dados em campo.

$\mathrm{Na}$ análise das patologias encontradas foram utilizadas pesquisas bibliográficas, livros, revistas, artigos, dissertações e teses, estudos feitos por instituições, manuais técnicos e normas da ABNT que abrangesse o tema e o sistema construtivo em estudo.

\subsection{Local de Estudo}

\subsubsection{Empreendimento I}

O empreendimento I é localizado na BR 316 na zona sul da cidade em estudo, caracterizado como loteamento com oitenta e oito blocos compostos de mil trezentos e sessenta e oito apartamentos, com 47,70 $\mathrm{m}^{2}$ todos os blocos com modelo de apartamento térreo e pavimento superior.

\subsubsection{Empreendimento II}

O empreendimento II está localizado no loteamento dos Morros III, em Teresina-PI, constituído de um mil e dezesseis apartamentos, divididos em oitenta e nove blocos, sendo trinta e oito blocos com dezesseis e cinquenta e um blocos com oito apartamentos. Todas as edificações apresentam pavimento térreo e pavimento superior com uma área de $43,11 \mathrm{~m}^{2}$.

\subsubsection{Empreendimento III}

O empreendimento III, é localizado na zona sul de Teresina, consiste em um residencial de apartamentos da tipologia "térreo + 1 pavimento", composto por vinte e oito blocos, sendo vinte e dois de dois blocos de dezesseis apartamentos e seis blocos de oito apartamentos, cada apartamento possuindo $46,00 \mathrm{~m}^{2}$.

\subsection{Coleta de dados}

\subsubsection{Ficha de identificação}

Para o empreendimento III foi realizada uma vistoria acompanhada por um Engenheiro Civil da Caixa. A escolha dos blocos para visitação foi de acordo com os pareceres gerados por reclamações de usuários nos canais de denúncias Caixa e emitidos pela célula de Gestão de Qualidade e Danos Físicos da empresa. Outro fator que dificultou bastante a vistoria além da localização do empreendimento, que fica numa zona de difícil acesso da cidade, foi a falta de segurança, visto o 
histórico de violência do bairro.

Os levantamentos de dados em campo foram coletados e anotados através de uma ficha de presença de manifestações patológicas, descrevendo as características das manifestações observadas, munido também de prancheta, câmera fotográfica, caneta, lapiseira e a ficha de identificação.

A ficha para coleta de dados do empreendimento identifica a localização de cada ambiente analisado e a descrição das manifestações patológicas.

Quadro 1: Ficha da presença de manifestações do Autor, 2018.

\begin{tabular}{|l|c|c|c|}
\hline \multicolumn{4}{|c|}{ FICHA DE PRESENÇA DE MANIFESTAÇÕES PATOLÓGICAS } \\
\hline QUADRA & BLOCO & MANIFESTAÇÃO & LOCAL \\
\hline & & & \\
\cline { 3 - 4 } & & & \\
\cline { 3 - 5 } & & & \\
\hline
\end{tabular}

Com o preenchimento in loco da ficha, obteve-se informações e um nível de detalhamento das manifestações patológicas encontradas, e com o preenchimento da ficha nas quadras que se realizou a visita, foi gerada uma classificação para as manifestações, a fim de facilitar e organizar as descrições de cada uma.

Quadro 2: Exemplo de preenchimento da ficha do Autor, 2018.

\begin{tabular}{|c|c|c|c|}
\hline \multicolumn{4}{|c|}{ FICHA DE PRESENÇA DE MANIFESTAÇÕES PATOLÓGICAS } \\
\hline QUADRA & BLOCO & MANIFESTAÇÃO & LOCAL \\
\hline \multirow{2}{*}{$\mathrm{R}$} & \multirow{2}{*}{ BL 4} & Fissuras internas & Laje \\
\hline & & Fissuras Externas & Fachada \\
\hline \multirow[b]{2}{*}{$\mathrm{S}$} & \multirow[b]{2}{*}{ BL 2} & Infiltração & Cozinha \\
\hline & & $\begin{array}{l}\text { Falta de compatibilização de } \\
\text { projetos }\end{array}$ & - \\
\hline
\end{tabular}

As informações dos empreendimentos I e II foram coletadas junto a CAIXA sede de Teresina-PI. Foram dispostos dados como ficha resumo dos empreendimentos, fotografias das montagens dos painéis e da obra, pareceres da obra, dentre outros. Analisando todos os documentos foi possível organizar a situação de cada empreendimento e descrever as manifestações observadas através da fiscalização feita pelo Órgão responsável.

\subsubsection{Análise de dados}

Dessa forma, com o levantamento de dados em campo através da ficha de identificação e fotos, e as informações concedidas pelo órgão responsável, foi feito um alinhamento de dados, de forma a quantificar as manifestações patológicas encontradas e sugerir as adequadas soluções de acordo com a literatura disponível sobre o tema.

\section{RESULTADOS E DISCUSSÕES}

Com o levantamento in loco feito através da ficha de identificação e as informações coletadas na caixa econômica, as manifestações patológicas mais presentes foram as seguintes:

- $\quad$ Fissuras externas nos painéis;

- $\quad$ Fissuras internas nos painéis;

- Manchas nos painéis;

- Infiltrações nos painéis;

- Manifestações patológicas relacionadas com a concretagem;

- Manifestações patológicas em calçadas externas;

- $\quad$ Falta de compatibilização de projetos;

- Manifestações patológicas relacionadas com a montagem. 


\subsection{Manifestações encontradas}

\subsubsection{Manifestações patológicas relacionadas com a concretagem}

A parte interna dos apartamentos apresentou falha na concretagem deixando a armação exposta, com a má distribuição do concreto na viga ao lado. O mau posicionamento dos painéis durante a montagem ocasiona uma concretagem irregular na união com outros elementos estruturais, e ainda apresentam quebras podendo ter ocorrido durante sua montagem, desmolde e ou para adaptações de projetos.

\section{Empreendimento I}

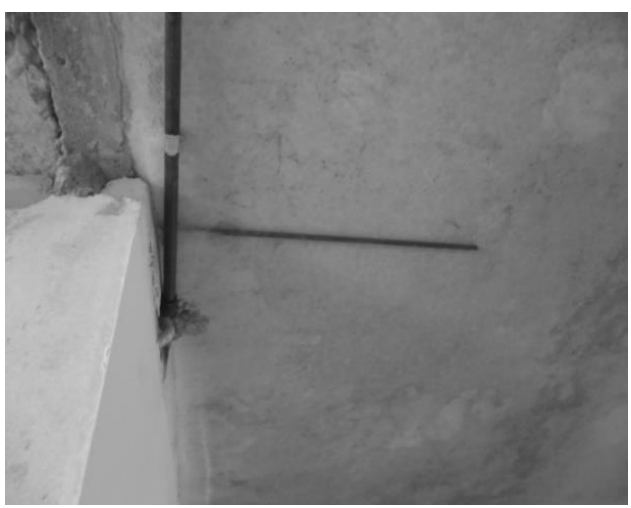

Figura 3: Barra de aço exposta e má distribuição de concreto do Acervo Caixa 2016.

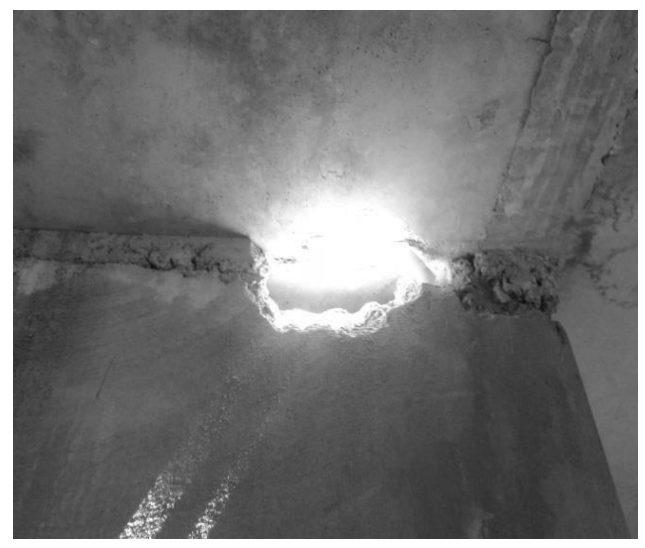

Figura 5: Má distribuição do concreto e painéis quebrados do Acervo Caixa 2016.

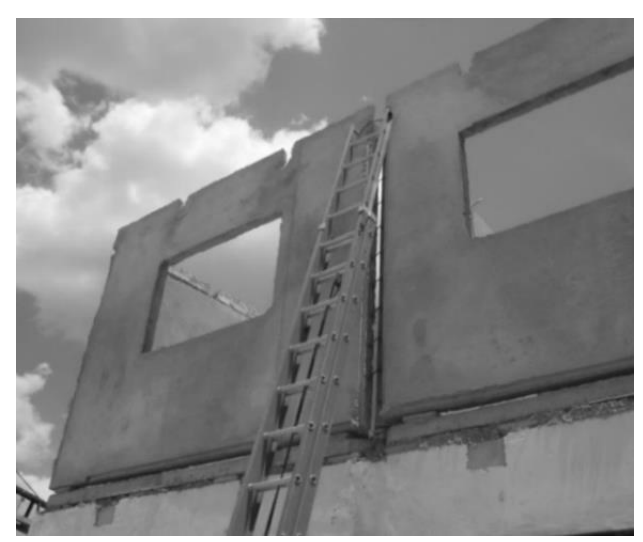

Figura 4: Painéis quebrados e desalinhados do Acervo Caixa 2016.

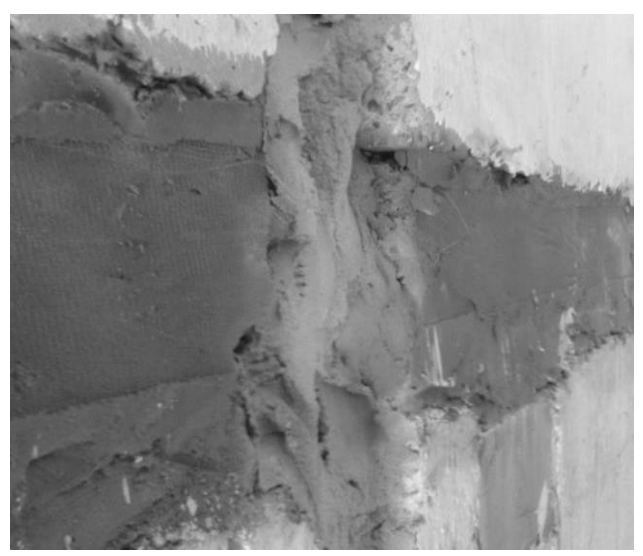

Figura 6: Detalhe do encontro entre painéis do Acervo Caixa 2016. 


\subsubsection{Falta de compatibilização de projetos}

A incompatibilidade do projeto de instalações sanitárias e o estrutural durante o posicionamento das peças para concretagem dos painéis resultou em aberturas não previstas para encaixe das tubulações, ocasionando peças quebradas e armações expostas.

Empreendimento I

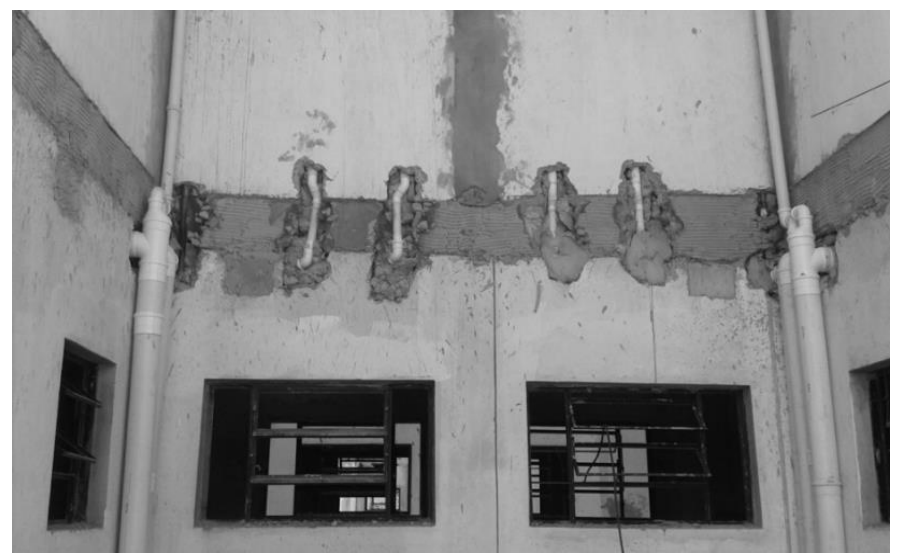

Figura 7: Rasgos nos painéis para inserir tubulações sanitárias do Acervo Caixa 2016.

\subsubsection{Manifestações patológicas relacionadas com a montagem}

O elemento estrutural de sustentação da laje estava alguns centímetros para fora do seu apoio, sacando do painel e transpassando o mesmo podendo ter sido falha de execução, movimentação da estrutura ou de falhas na concretagem.

\section{Empreendimento I}

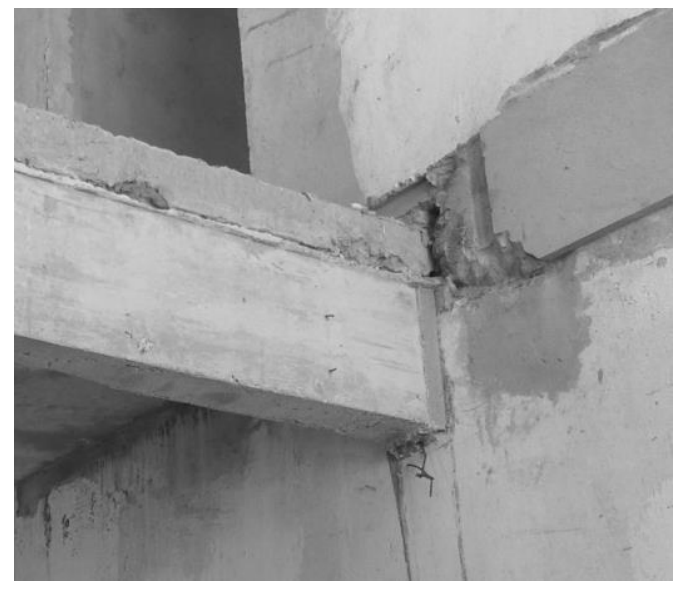

Figura 8: Detalhe da viga no ponto de afastamento do apoio do Acervo Caixa 2016.

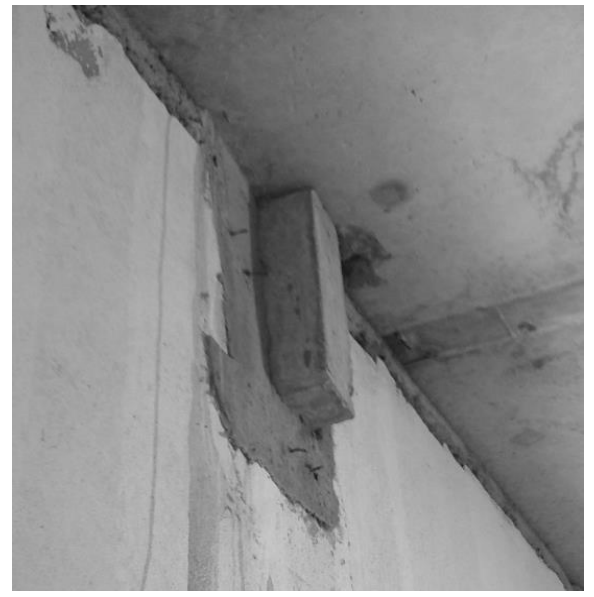

Figura 9: Viga atravessa o painel de apoio Acervo Caixa 2016. 


\subsubsection{Fissuras externas nos painéis}

Os painéis moldados e montados em sua posição para formar um apartamento apresentam fissuras, assim como a laje, podendo ser em decorrência durante o desmolde da peça ou cura do concreto (ver empreendimento II). Na fachada frontal observa-se a presença de rachaduras que se estendem do térreo a cobertura, na região de encontro de painéis. A causa pode estar relacionada à movimentação dos painéis ou falha da execução na montagem dos mesmos (ver empreendimento III).

Empreendimento III

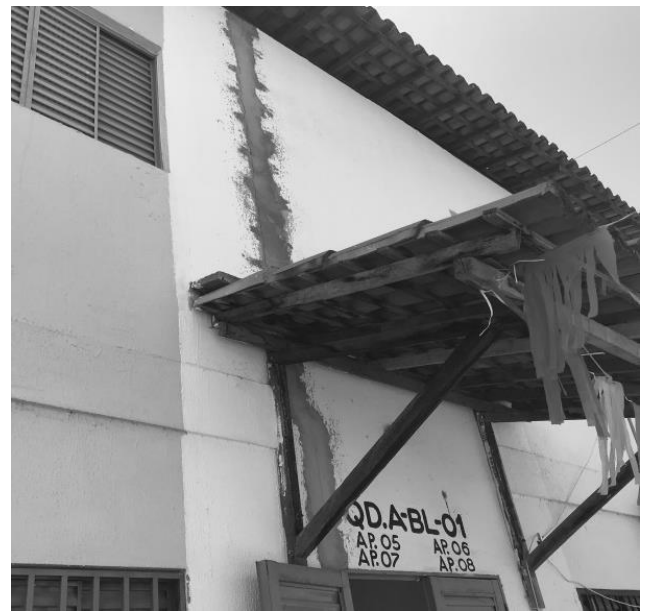

Figura 10: Fissura do térreo a cobertura na fachada do bloco do Autor 2018.

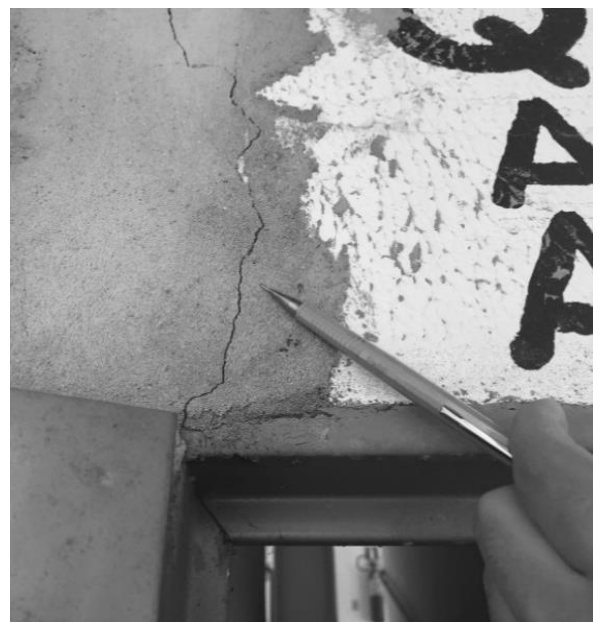

Figura 11: Detalhe da fissura acima da porta de acesso aos apartamentos do Autor 2018.

\subsubsection{Fissuras internas nos painéis}

Muitos painéis apresentam fissuras de diversas angulações e em locais diferentes que podem ter sido ocasionados por mau posicionamento durante a concretagem, cura inadequada do concreto e ausência de verga e contraverga. Entre os tipos há manifestações do encontro de lajes e painéis, entre painéis internos e rachaduras no piso cerâmico.

\section{Empreendimento I}

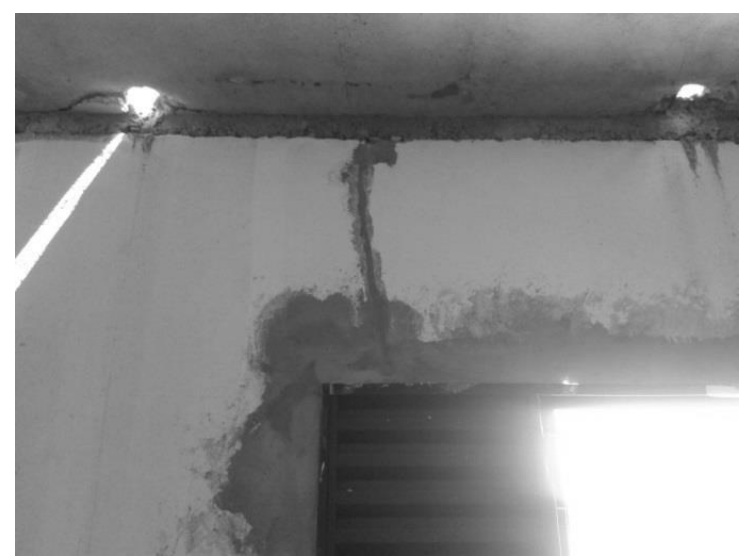

Figura 12: Fissuras verticais acima da janela do Acervo Caixa 2016.

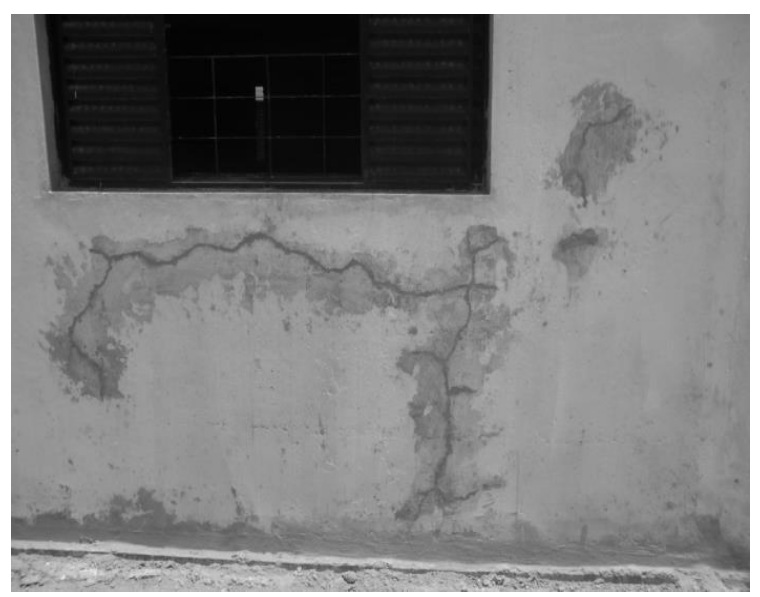

Figura 13: Fissuras horizontais e verticais abaixo da janela do Acervo Caixa 2016. 


\section{CBPAT 2020 \\ CONGRESSO BRASILEIRO DE PATOLOGIA DAS CONSTRUÇÕES \\ DE 15 A 17 DE ABRIL | FORTALEZA - CE

Empreendimento III

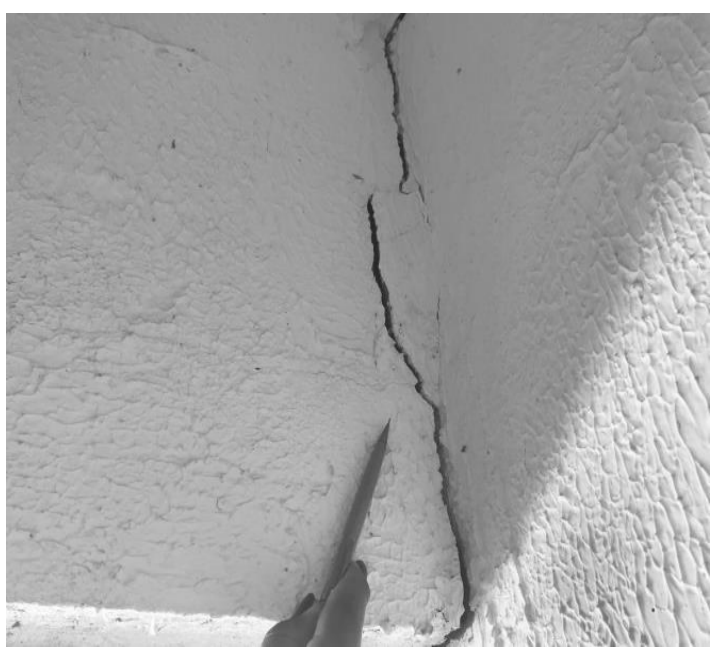

Figura 14: Detalhe da rachadura do Autor 2018.

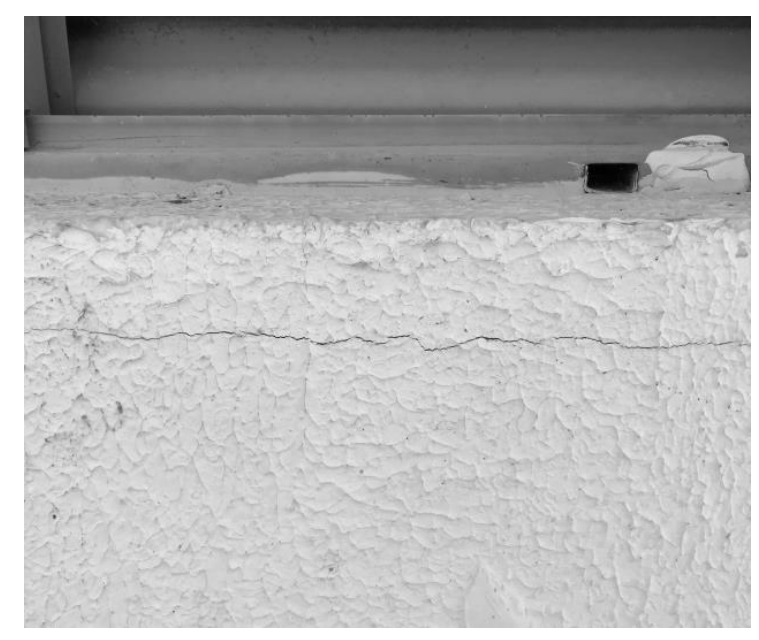

Figura 16: Fissuras abaixo de janela do Autor 2018.

Figura 17: Fissuras no encontro de painéis internos do Autor 2018

Figura 15: Afastamento do encontrode viga com painel do Autor 2018.

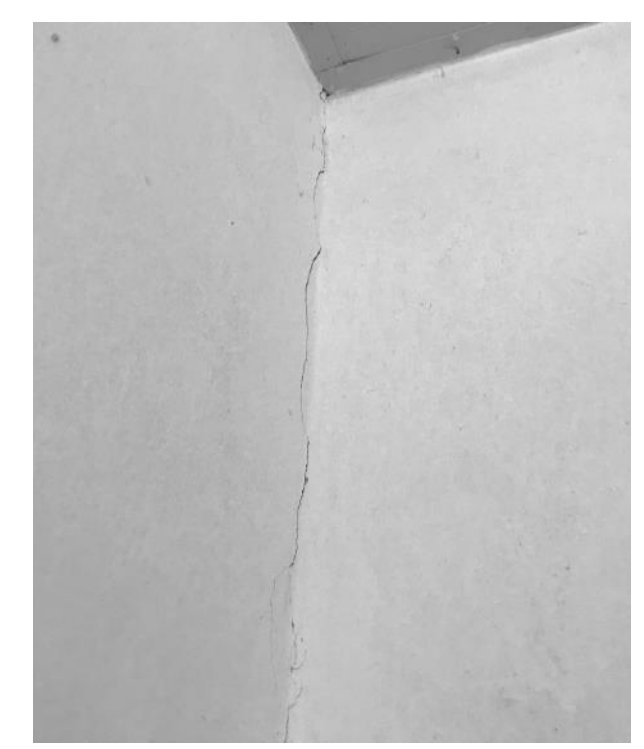

\subsection{Descrição das ocorrências das manifestações patológicas - Empreendimento III}

Quadro 3: Manifestações patológicas Empreendimento III do Autor 2018.

\begin{tabular}{|c|c|c|c|}
\hline \multicolumn{4}{|c|}{ FICHA PRESENÇA DE MANIFESTAÇÕES PATOLÓGICAS } \\
\hline QUADRA & BLOCO & MANIFESTAÇÃO & LOCAL \\
\hline A & BL 01 & Fissuras externas nos painéis & Fachada frontal \\
\cline { 3 - 4 } & Apts 05 a 08 & Fissuras internas nos painéis & $\begin{array}{c}\text { Escada - Hall de acesso a apt } \\
\text { superiores }\end{array}$ \\
\cline { 3 - 4 } & & Manifestações patológicas em & Perímetro do bloco \\
& & Malçadas externas & Fachada lateral direita \\
\cline { 3 - 4 } & & Infiltrações nos painéis & Cozinha - Apt 02 e 04 \\
\cline { 2 - 4 } & BL 04 & Fissuras externas nos painéis & Fachada lateral direita \\
\hline
\end{tabular}




\begin{tabular}{|c|c|c|}
\hline \multirow[t]{5}{*}{ Apt 05 a 08} & $\begin{array}{c}\text { Manifestações patológicas em } \\
\text { calçadas externas }\end{array}$ & Perímetro do bloco \\
\hline & \multirow[t]{4}{*}{ Fissuras internas nos painéis } & Abaixo das esquadrias \\
\hline & & Encontro de painéis apt. 07 \\
\hline & & Laje \\
\hline & & Piso \\
\hline $\begin{array}{c}\text { BL } 11 \\
\text { Apt. } 05 \text { a } 08\end{array}$ & Infiltrações nos painéis & $\begin{array}{l}\text { Hall dos apartamentos superiores } \\
\text { e na cozinha das apts } 02 \text { e } 04\end{array}$ \\
\hline
\end{tabular}

\subsubsection{Recuperações realizadas no Empreendimentos}

Visamos que a correta execução de qualquer método construtivo aliado com a qualidade dos materiais, é evitada o aparecimento de manifestações patológicas. E quando surgem é necessário uma medida correta para tratar aquele tipo de manifestação, o que se não cuidado podem se agravar e se transformarem em outras manifestações mais complexas de solução.

As sugestões descritas a seguir são caracterizadas por (Helene, 2002). Com base nas observações feitas in loco foi caracterizado as possíveis causas das manifestações, e comparadas com as que mais se assemelham as descritas na literatura, e assim, sugeridas as correções, visto que são necessários ensaios e vistorias mais detalhadas para a aplicação da melhor correção.

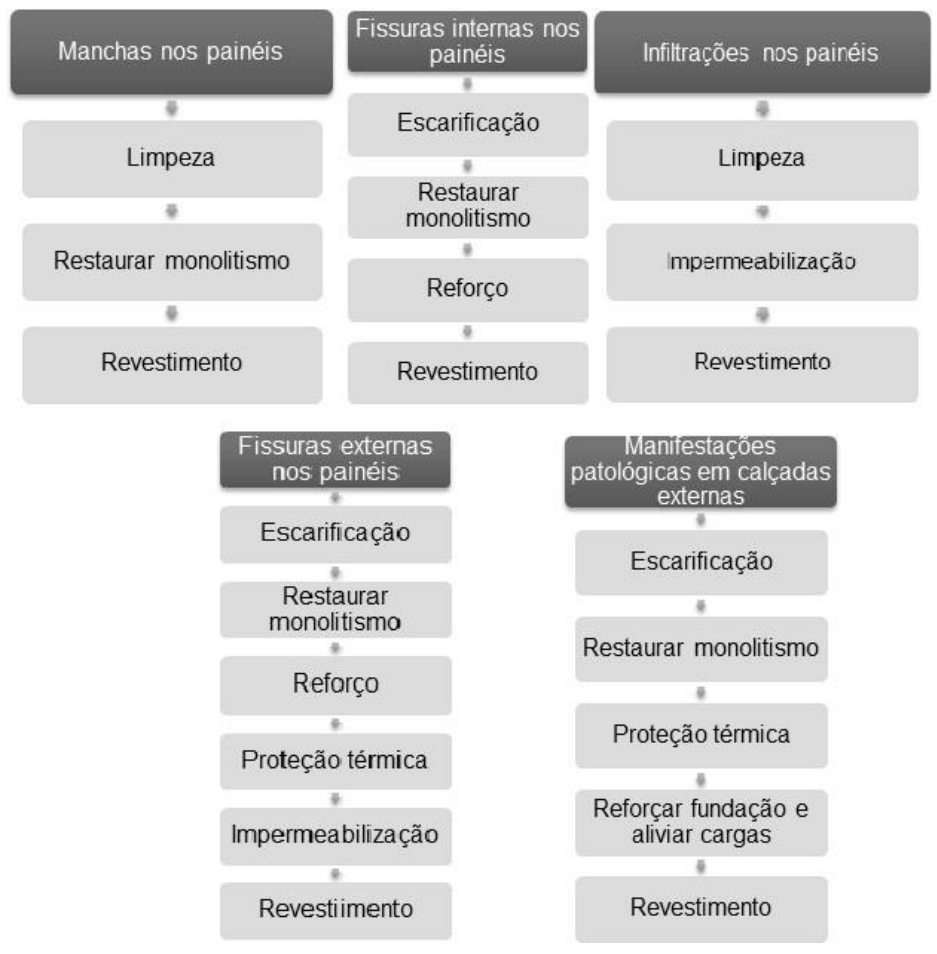

Figura 18: Fluxogramas de etapas para correções das manifestações patológicas do Autor 2018.

Com o crescimento do setor habitacional no Brasil, surgiram novas tecnologias construtivas. Buscou-se analisar de forma detalhada o sistema de painéis pré-moldados denominado Casa Express por ser um sistema muito utilizado do estado do Piauí e com grande presença na cidade de Teresina. Por se tratar de uma tecnologia nova foi necessário trazer informações sobre as manifestações patológicas que surgiram nesses empreendimentos habitacionais.

O objetivo principal do trabalho foi a identificação das causas das manifestações patológicas apresentadas no sistema de painéis pré-moldados Casa Express. Os resultados expostos acima mostram que o objetivo foi alcançado de forma 
satisfatória para todas as manifestações identificadas.

O estudo indicou que houve a ocorrência de patologia estrutural mais grave em apenas um bloco de um dos empreendimentos e que a causa estava ligada a problemas de execução, sendo que a solução adotada pela construtora para o reparo do mesmo se mostrou eficiente, tendo em vista a estabilidade dos danos na estrutura após a intervenção.

Desta forma, conclui-se que, apesar de não normatizado, o sistema inovador Casa Express tem funcionado efetivamente e que os problemas encontrados estão relacionados principalmente com falha na concretagem e na montagem dos painéis. As manifestações patológicas mais presentes foram: fissuras, infiltrações e incompatibilidade de projetos.

\section{AGRADECIMENTOS}

Agradeço primeiramente a Deus pela força que me destes durante toda essa caminhada dos meus estudos e continua me proporcionando muitas bençãos em minha vida. A minha família, que estiveram me apoiando com muito amor os meus estudos. A todos os meus ex-professores que sempre compartilharam seus conhecimentos e me incentivaram a dar o meu melhor. A Mestre Carol Chaves, pelo suporte durante o desenvolvimento deste trabalho, como também pela experiência e conhecimento que me foi transmitido, pela paciência, pelo tempo e pelos materiais disponibilizados.

\section{REFERÊNCIAS}

DATec $\mathrm{N}^{\circ}$ 23-A. Painéis estruturais pré-moldados Casa Express, mistos de concreto armado e lajotas cerâmicas - Tipo A. 2016.

HELENE, Paulo. Manual para reparo, reforço e proteção de estruturas de concreto. São Paulo: Pini, 2002.

SOUZA, Vicente C. M.; RIPPER, Thomaz. Patologia, recuperação e reforço de estruturas de concreto. São Paulo: Pini, 1998. 